\title{
Knowledge and Attitudes About Travel Medicine in Latin America in the Context of COVID-19: A Cross- Sectional Study
}

\author{
Esmailyn Castillo Santana ${ }^{1 \oplus}$, Margareth Catoia Varela ${ }^{1 \oplus}$, Yocastia de Jesús Arámboles ${ }^{2^{*} \odot}$, Anderson \\ Suarez-Rodríguez $^{\circledR}{ }^{\circledR}$, Marcellus Dias da Costa ${ }^{1}$ \\ 'Laboratório de Pesquisa em Imunização e Vigilância em Saúde (LIVS), Instituto Nacional de Infectologia Evandro \\ Chagas, Fiocruz, Rio de Janeiro, Brazil \\ ${ }^{2}$ Ciencias de la Salud, Instituto Tecnológico de Santo Domingo, Santo Domingo, Dominican Republic \\ ${ }^{3}$ Escuela de Enfermería, EDP University of Puerto Rico, San Juan, Puerto Rico
}

Corresponding Author: Yocastia de Jesús Arámboles, MD, Professor, Ciencias de la Salud, Instituto Tecnológico de Santo Domingo. 49 Los Proceres Avenue, Jardines del Norte, Santo Domingo (10602), Dominican Republic. Tel: +18495423114, Email: yocastiadejesus@gmail.com

Received May 24, 2021; Accepted July 17, 2021; Online Published August 11, 2021

\begin{abstract}
Introduction: Travel Medicine specialty has existed in Latin American for more than 25 years. The creation of the Latin American Society of Travel Medicine (SLAMVI) stimulated medical education in this discipline, through research and scientific publications. However, Travel Medicine is practically unknown to Latin Americans.

Methods: Latin Americans ( $n=9487$ ) completed an online survey of ten questions from nine countries of the region to determine the knowledge of the population about the existence of this specialty and their attitudes about it.

Results: Although more than $90 \%$ of those surveyed knew that traveling to certain countries requires to receive certain vaccines, less than $30 \%$ had heard of the specialty of Travel Medicine. After knowing the definition and objectives of the specialty, more than $90 \%$ of the participants considered it important to carry out a pre-travel consultation with a specialist.

Conclusion: The lack of knowledge of the specialty is the main barrier to Latin Americans to have access to Travel Medicine consultation. It is necessary to publicize the specialty, make the population aware of the importance of pre- and post-travel consultation, as well as the creation of this service in more public hospitals in Latin America.

Keywords: Knowledge, Travel, Vaccines, Immunization
\end{abstract}

Citation: Castillo Santana E, Varela MC, de Jesús Arámboles Y, Suarez-Rodríguez A, da Costa MD. Knowledge and attitudes about travel medicine in latin america in the context of COVID-19: A cross-sectional study. Int J Travel Med Glob Health. 2021;9(3):119-123. doi:10.34172/ijtmgh.2021.20.

\section{Introduction}

Travel Medicine is an interdisciplinary specialty that deals not only with the prevention of infectious diseases during travel, but also with personal safety and the prevention of environmental risks in national and international destinations. ${ }^{1}$ The increase in the number of travelers, the diversity of both their itineraries, and the activities carried out during the trips are just some of the factors that contributed to the birth of this specialty. Furthermore, travelers can import diseases to their places of origin, which can be spread such as COVID-19, yellow fever, measles, sexually transmitted infections (STIs), and others. These situations justify the need for the pr- and post-travel consultation. ${ }^{2}$

Travel medicine was created as a new discipline in the 1970s due to the growing interest in illnesses of European and North
American travellers. ${ }^{3}$ Despite the existence of regional and world scientific societies such as the Latin American Society of Travel Medicine (SLAMVI) and the International Society of Travel Medicine (ISTM) dedicated to the diffusion of this specialty, ${ }^{4,5}$ it is not well known by Latin Americans and few data are available on the knowledge, attitudes, and practices of travelers from this region with regard to travel-related infectious diseases from this area. ${ }^{6}$

In the context of the COVID-19, Travel Medicine receives a special highlight. The pandemic has plummeted air travel and the tourism industry, and it will change the way we do Travel Medicine, there is hope though: travel and Travel Medicine will recover from this crisis once effective vaccines and therapeutics are widely available. ${ }^{7}$ In the midst of this global public health crisis, it is important to make the specialty of

Copyright $(C 2021$ The Author(s). This is an open-access article distributed under the terms of the Creative Commons Attribution License (http:// creativecommons.org/licenses/by/4.0), which permits unrestricted use, distribution, and reproduction in any medium, provided the original work is properly cited. 
Travel Medicine known to those who still do not know it, so that they can also make a pre and post-trip consultation. The main objective of this research was to determine the knowledge of Latin Americans about the existence of Travel Medicine and their attitudes about it.

\section{Methods}

We conducted a cross-sectional study online in nine Latin American countries, from November 20 to December 20, 2020. The sample was non-probabilistic for convenience. The inclusion criteria were being over 18 years of age and being a citizen of a Latin American country. The exclusion criteria were being a citizen of a Latin American country but living in a country outside of the region. Participants were recruited through social media, including WhatsApp, Facebook, and Instagram. Study data and data gathering form links were collected and managed using REDCap electronic data capture tools from that same institution. ${ }^{8,9}$ For this study, Latin American is composed of Mexico, Central America, Latin Caribbean, Andean Area, Brazil, and Southern Cone.

After granting electronic informed consent, 9487 respondents from Argentina, Brazil, Colombia, Dominican Republic, Ecuador, Honduras, Mexico, Panama, and Peru completed a form with ten questions. The first five questions were on demographic data (gender, age, country, level of education, healthcare professionals), followed by five specifics of yes or no questions about travel medicine (knowledge of both the existence of the specialty and the need for pretravel vaccination, having consulted with a specialist in travel medicine in the past, they considered it important to make a pre-travel consultation and the willingness to pay to be vaccinated). Not all the participants had access to all the questions, as they appeared based on the participants' responses. Only those who knew the travel medicine specialty had access to the question about having made a pre-travel consultation. The average duration to complete the form was one min.

The country with the highest number of participants was Brazil with 3290 and the lowest Ecuador with 300 participants. Due to the lack of demographic proportionality between the different countries, as well as the differences between the realities of these, it was not possible to make exact comparisons between them. We analyzed the distribution of the responses throughout the data set, summarizing categorical variables such as counts and percentages, using the software $\mathrm{R}$ version 4.0.3 with table one package, and the association measures were calculated using the chi-square or Fisher's exact test. ${ }^{10}$ The tables include the information of the respondents for each question, not all the participants answered all the questions.

\section{Results}

\section{Population Characteristics}

Of the 9487 participants, 6338 (68.1\%) were female, 4074 (42.9\%) between 25 and 44 years old, age mean (SD) 36.07, $2788(29.8 \%)$ had some college or associate degree and 2824 $(30.0 \%)$ were healthcare professionals. Other population characteristics are listed in Table 1.

\section{Travel Medicine}

Only 2461 (26.2\%) of the surveyed participants knew about the travel medicine specialty. Argentina had the highest proportion of positive responses (256 of 685 surveyed, $37.4 \%$ ), and the lowest proportion belonged to the Colombian participants (74 of 426 surveyed, 17.4\%) (Table 2).

Concerning the knowledge about pre-travel vaccination most of the surveyed ones gave a positive answer, 8447 (90.0\%). Brazil had the highest proportion of positive responses (3117 of 3237 surveyed, 96,3\%) and the Dominican Republic had the lowest proportion (2072 of 2570 surveyed, $80.6 \%$ ).

Only $719(29.7 \%)$ of the respondents had consulted with a specialist in Travel Medicine before traveling. The country with the highest proportion of positive responses was Honduras (36 of 72 surveyed, 50\%) and the lowest proportion belonged to Peru (22 of 119 surveyed,18.5\%).

After knowing the definition and objectives of the Travel Medicine specialty, 8626 (92.3\%) participants considered it important to carry out a pretravel consultation with a specialist. The country with the highest proportion of positive answers was Mexico (769 of 804, 95.6\%) and Brazil had the lowest (2934 of 3232, 90.8\%).

\section{Discussion}

Latin America is one of the regions with the most cases of COVID-19, ${ }^{11}$ which translates into a differentiated perception of the disease and the need for measures to control it. The perception of many Latin Americans in relation to vaccination changed due to the experience of the pandemic as was demonstrated in the study "Immunization in Latin America in the context of COVID-19: a regional survey" (personal communication February 25, 2021 -Vaccine X Journal). It is to be expected that the pandemic will also influence the way Latin Americans prepare for future trips, as shown in the article "The COVID-19 pandemic offers a key moment to reflect on travel medicine practice", potential travelers will expect to receive detailed practical information on preventive and regulatory measures, travel restrictions and countryspecific requirements such as testing for protective antibodies, 'immunity passports' and later the proof of vaccination. ${ }^{12}$ The pandemic taught many people that humans are also vectors, we can transport infectious agents from one country to another, a situation that depending on various factors can result in a global public health crisis like the one we are currently experiencing with the COVID-19. ${ }^{13}$

Our results coincide with those published by Guerrero-Lillo et al, who showed that knowledge, attitudes, and practices about travel medicine in international travelers and medical students from Chile are deficient; $78.5 \%$ of the participants stated no knowledge of travel medicine, ${ }^{6}$ here it was $73.8 \%$. In relation to pre-travel consultation, our findings are comparable with those previously reported by Wilder-Smith et al, $31 \%$ of the surveyed participants had sought pretravel health advice, here it was $29.7 \%{ }^{14}$

Pretravel vaccination is one of the pillars of travel medicine. Several of the vaccines that exist for the protection of travelers are not part of the national vaccination schedule of Latin 
Table 1. Description of Participants and Relationship With Knowledge About the Existence of Travel Medicine

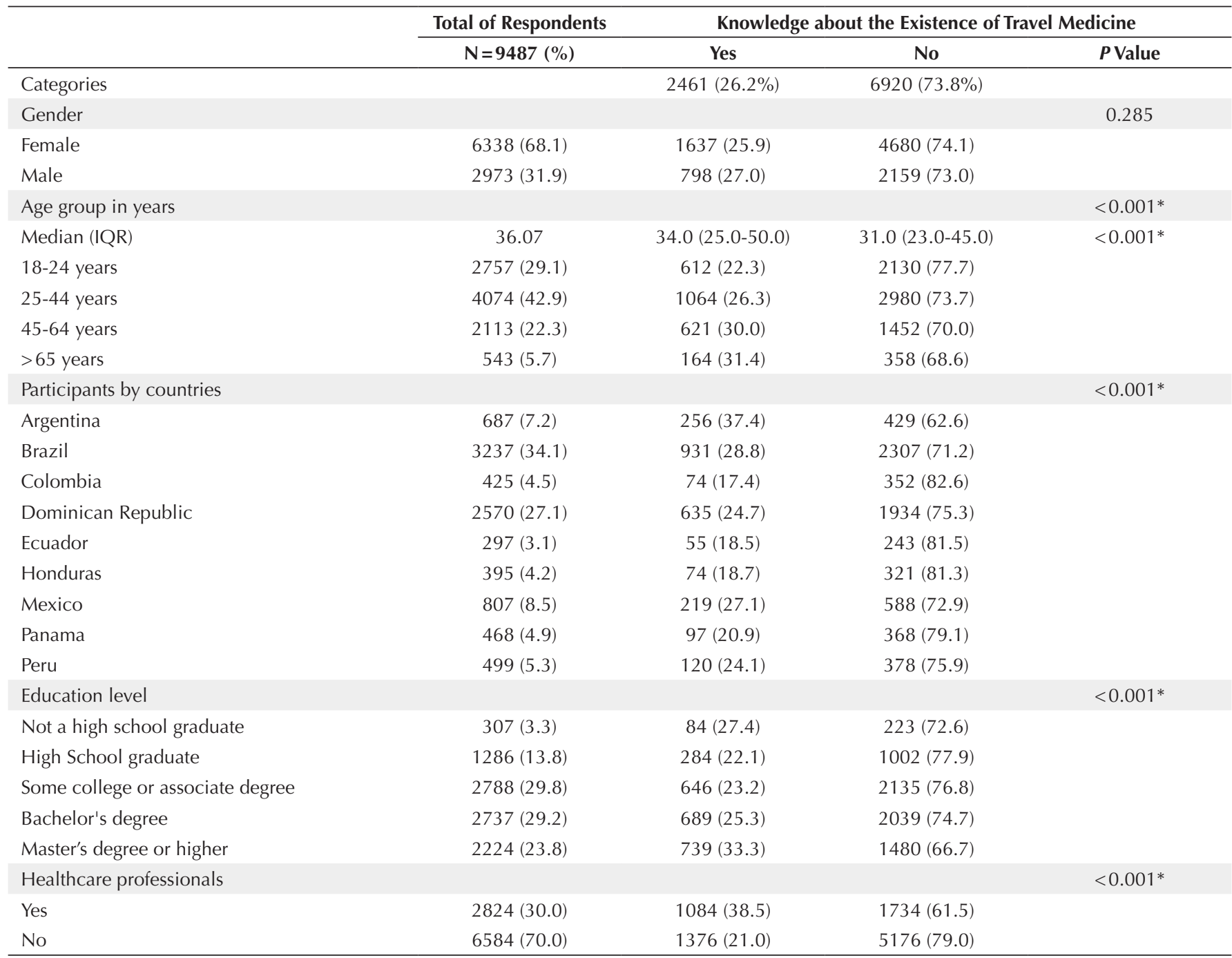

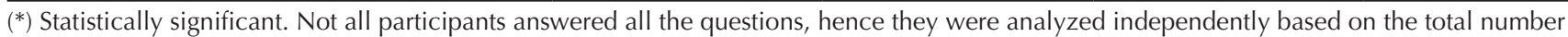
of respondents for each question. The reading of the data of the total of participants is vertical, while the relationship of the sociodemographic variables with the Knowledge of Travel Medicine is horizontal.

Table 2. Survey Questions About Travel Medicine

\begin{tabular}{lcc}
\hline Questions & Participants & $P$ Value \\
\hline Knowledge about the need for vaccination to travel to certain countries (\%) & $8447(90.0)$ \\
Yes & $938(10.0)$ \\
No & $2461(26.2)$ \\
Knowledge about the existence of the travel medicine specialty $(\%)$ & $6920(73.8)$ \\
Yes & \\
No & $719(29.7)$ \\
They have consulted with a specialist in travel medicine before traveling (\%) & $1703(70.3)$ \\
Yes & \\
No & $8626(92.3)$ \\
After knowing the definition and objectives of the travel medicine specialty, they consider it & \\
important to consult one of those specialists $(\%)$ & $723(7.7)$ \\
Yes & \\
No & $7214(77.2)$ \\
Willing to pay to be vaccinated $(\%)$ & $2136(22.8)$ \\
Yes & $<0.001^{*}$ \\
No &
\end{tabular}

(*) Statistically significant. 
American countries but are available in private vaccination centers. ${ }^{15}$ As for the surveyed ones, 7214 (77.2\%) of them were willing to pay to be vaccinated, which suggests that despite vaccination not being available in the public health services and not having the habit of making a pretravel consultation, Latin Americans are willing to adopt the necessary preventive measures to reduce the risk of becoming ill as a result of the trip, and thus avoid the spread of infectious diseases when returning to their countries.

Unlike industrialized countries where there are more studies on pre-travel consultations in travel medicine centers, ${ }^{16}$ a limited number of studies have been conducted in the region. From 1984 to 2008, 92 published papers were identified through Medline applying for the Medical Subject Heading "Travel Medicine" with their provenance in Latin American countries; this represented $1.7 \%$ of the total number of publications on "Travel Medicine" in the world found through Medline during the same period. ${ }^{17}$ The study "Monitoring Closing the Gap in Travel Medicine: need to focus on Africa and Latin America" showed that there were totally 90 scientific publications in 2008 and 95 in 2017 about Travel Medicine. The region with the highest contributions of scientific publications in the Journal of Travel Medicine is Europe, followed by North America. In the both years, authors from Latin America made contributions of up to only $2 \%$. The proportion has not changed significantly over the ten years. Despite the shift in high travel volumes in recent years to new emerging economies, and increasing travel out of Latin America, the lack of publications over the years from this region underpins the gaps in travel medicine. Strategies should be developed to encourage enhanced Travel Medicine research in Latin America. ${ }^{18}$

The pandemic may change the way of doing travel medicine, worldwide, both for health professionals and for patients. Of the 2824 healthcare professionals surveyed, only 1084 (38.5\%) knew about Travel Medicine. It is necessary to make travel medicine as a specialty known to the general population as well as including it in the programs of medical schools to train doctors as another vision as Tissingh suggests: Today's medical students will practice medicine in a globalized world, where an understanding of Travel Medicine and global health will be vital to work in tomorrow's world. ${ }^{19}$ Those professionals will encourage patients to carry out the Travel Medicine consultation, which would increase the number of people who knowing and taking advantage of the travel medicine specialty.

Our study has limitations, in some countries, participation was low in relation to the total population, respondents may not be representative of all residents of those countries, which could bias the findings. Meanwhile, not all participants answered all the questions, thus they were analyzed independently based on the total number of respondents for each question.

\section{Conclusion}

Most participants were unaware of the existence of the travel medicine specialty, the lack of knowledge is the main barrier

\section{Research Highlights}

\section{What Is Already Known?}

- Most Latin Americans have never heard of Travel Medicine.

- The lack of knowledge is the main barrier for Latin Americans to get access to Travel Medicine consultations.

- It is necessary to promote the specialty and make the population aware of the importance of pre-and posttravel consultation.

\section{What Does This Study Add?}

- The Data is on the perception of Latin Americans about travel Medicine after knowing the definition and the objectives of this specialty.

- $\quad$ Bibliographic reference on Knowledge and Attitudes About Travel Medicine in Latin America.

for Latin Americans to get access to this service. Despite this, after knowing the definition and objectives of the specialty, most of them considered it important to carry out a pre-travel consultation with a specialist and are willing to pay to get vaccinated. The COVID-19 pandemic may set a precedent in travel medicine in Latin America, everything will depend on how authorities and health professionals of in the region take advantage of the pandemic in favor of the promotion of this specialty and make the population aware of the importance of pre- and post-travel consultation, to guarantee the preservation of the traveller's health, as well as avoiding the spread of infectious diseases through travellers.

\section{Authors' Contributions}

ECS: Conceptualization, methodology, investigation, writingoriginal draft preparation; MCV: Software and data curation; YJA: Investigation, ASR: Investigation; MDC: Conceptualization, methodology, writing- reviewing and editing.

\section{Conflict of Interests Disclosures}

The authors declare no conflict of interest.

\section{Ethical Approval}

This study was approved by the institutional review board of the National Institute of Infectious Diseases Evandro Chagas, Fiocruz.

\section{Funding/Support}

This study did not receive any financial support.

\section{References}

1. Hill DR, Ericsson CD, Pearson RD, et al. The practice of travel medicine: guidelines by the Infectious Diseases Society of America. Clin Infect Dis. 2006;43(12):1499-1539. doi:10.1086/508782.

2. Freedman DO, Weld LH, Kozarsky PE, et al. Spectrum of disease and relation to place of exposure among ill returned travelers. N Engl J Med. 2006;354(2):119-130. doi:10.1056/NEJMoa051331.

3. Buck G, Steffen R. History of the development of Travel Medicine as a new discipline. In: Wilder-Smith A, Schwartz E, Shawn M, eds. Travel Medicine: Tales Behind the Science. 
Oxford: Elsevier; 2007. p.71-72.

4. Sociedad Latinoamericana de Medicina del Viajero. Objetivos, 2021; http://slamvi.org/. Accessed June 24, 2021.

5. The International Society of Travel Medicine. Mission and Vision Statement, 2021; https://www.istm.org/aboutistm. Accessed June 24, 2021.

6. Guerrero-Lillo L, Medrano-Díaz J, Pérez C, Chacón R, SilvaUrra J, Rodriguez-Morales AJ. Knowledge, attitudes, and practices evaluation about travel medicine in international travelers and medical students in Chile. J Travel Med. 2009;16(1):60-63. doi:10.1111/j.1708-8305.2008.00263.x.

7. Leong WY. COVID-19's impact on travel medicine surpasses that of all other emerging viral diseases. J Travel Med. 2020;27(8):taaa221. doi:10.1093/jtm/taaa221.

8. Harris PA, Taylor R, Thielke R, Payne J, Gonzalez N, Conde JG. Research electronic data capture (REDCap)--a metadatadriven methodology and workflow process for providing translational research informatics support. J Biomed Inform. 2009;42(2):377-381. doi:10.1016/j.jbi.2008.08.010.

9. Harris PA, Taylor R, Minor BL, et al. The REDCap consortium: building an international community of software platform partners. J Biomed Inform. 2019;95:103208. doi:10.1016/j. jbi.2019.103208.

10. R Core Team. R: A language and environment for statistical computing. Vienna, Austria: R Foundation for Statistical Computing; 2014. http://www.R-project.org/. Accessed February 6, 2021.

11. Johns Hopkins Coronavirus Resource Center. COVID-19 dashboard. 2021; https://coronavirus.jhu.edu/map.html. Accessed
May 2, 2021.

12. Hatz C, Bühler S, Farnham A. The COVID-19 pandemic offers a key moment to reflect on travel medicine practice. J Travel Med. 2020;27(8):taaa149. doi:10.1093/jtm/taaa149.

13. Bogoch, II, Watts A, Thomas-Bachli A, Huber C, Kraemer MUG, Khan K. Pneumonia of unknown aetiology in Wuhan, China: potential for international spread via commercial air travel. J Travel Med. 2020;27(2):taaa008. doi:10.1093/jtm/ taaa008.

14. Wilder-Smith A, Khairullah NS, Song JH, Chen CY, Torresi J. Travel health knowledge, attitudes and practices among Australasian travelers. J Travel Med. 2004;11(1):9-15. doi:10.2310/7060.2004.13600.

15. Schellack N, van der Sandt N, Modau T, Pople T, Meyer JC. Travel vaccines: information for health care practitioners. SA Pharm J. 2016;83(10):17-26. doi:10.10520/ejc199084.

16. Weitzel T. Profile and complexity of travel medicine consultations in Chile: unicentric cross-sectional study. BMJ Open. 2020;10(9):e037903. doi:10.1136/bmjopen-2020-037903.

17. Rodriguez-Morales AJ, Zuckerman JN. Extending across continents: travel medicine and Latin America. Travel Med Infect Dis. 2012;10(2):55-56. doi:10.1016/j.tmaid.2012.02.002.

18. Leong WY. Monitoring 'closing the gap in travel medicine': need to focus on Africa and Latin America. J Travel Med. 2019;26(3):tay149. doi:10.1093/jtm/tay149.

19. Tissingh EK. Medical education, global health and travel medicine: a modern student's experience. Travel Med Infect Dis. 2009;7(1):15-18. doi:10.1016/j.tmaid.2008.12.001. 